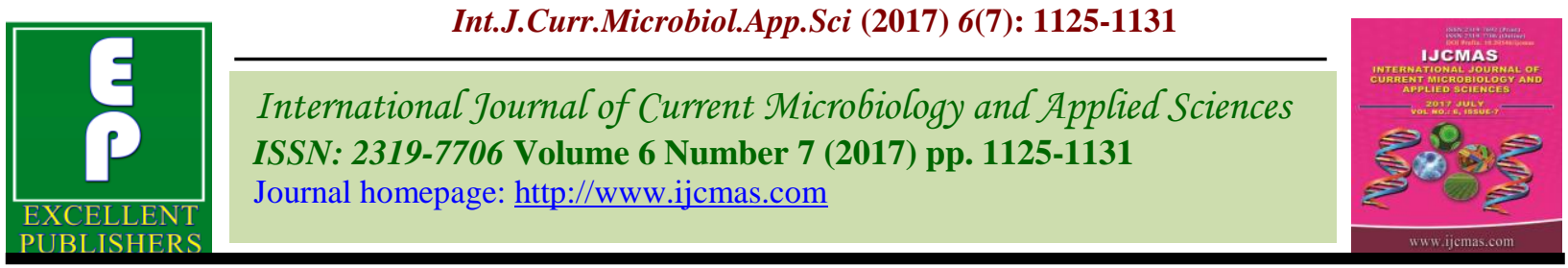

Original Research Article

https://doi.org/10.20546/ijcmas.2017.607.136

\title{
Analysis of Physico-Chemical Properties of Natural Food Colours from Fruits and Vegetables
}

\author{
P. Srilatha*, Butti Prabhakar, K. Umamaheswar and T.N.V.K.V. Prasad \\ Department of Post Graduate and Research Center, PJTSAU, Rajendranagar, Hyderabad- India \\ *Corresponding author
}

\author{
A B S T R A C T
}

\begin{tabular}{|c|}
\hline Keywords \\
\hline $\begin{array}{l}\text { Physico-chemical } \\
\text { properties, Natural } \\
\text { food colours, } \\
\text { SEM, Infrared } \\
\text { drying, Fruits and } \\
\text { Vegetable. }\end{array}$ \\
\hline Article Info \\
\hline $\begin{array}{l}\text { Accepted: } \\
\text { 17 June } 2017 \\
\text { Available Online: } \\
\text { 10 July } 2017\end{array}$ \\
\hline
\end{tabular}

\section{Introduction}

Color becomes the most sensitive part of any commodity not only for its appeal but also it enhances consumer acceptability. The demand for natural colours is increasing day by day because of awareness of positive health benefit out of natural compounds (Chattopadhyay et al., 2008). The organic colour stuffs are obtained from roots, stems, leaves, barks, flowers and berries of various plants and from certain insects and shellfish. The inorganic pigments are insoluble salts which are precipitated (Paul et al., 1996). There is a worldwide trend towards the use of natural additives and food colourant in food applications (Ghorpade et al., 1995). Nanotechnology describes materials, devices and systems with structures and components exhibiting new and significantly improved physical, chemical and biological properties as well as the phenomena and processes enabled by the ability to control properties at nanoscale (Miyazaki and Islam, 2007).

A range of nano techniques and materials are being developed to control over food character traits (Gardener, 2002). Inorganic nanomaterials are stable under harsh process conditions but also generally regarded as safe to human beings and animals (Stoimenov et al., 2002; Fu et al., 2005). Potential applications of nanotechnology are formulation of food products, food packaging 
applications and new materials for food equipments, new sanitizers and also water purification (Enculescu et al., 2008).

\section{Materials and Methods}

\section{Raw materials}

The fruits (papaya and black grapes) and vegetables (tomato and beet root) were procured from local market. Chemicals used in this experimentation and analysis were of food grade, purchased from standard Indian companies.

\section{Preparation}

Fruits (papaya and black grapes) and vegetables (tomato and beetroot) of each $1 \mathrm{~kg}$ were thoroughly washed in hot water and were cut into thin pieces. These pieces are placed in separate trays and were subjected to Infrared (IR) drying. After drying, the samples were cooled and grinded in a conventional grinder into fine powder.

\section{Synthesis of color nano particles}

In the present study NFCs were synthesized using dry powders from selected fruits (papaya and black grapes) and vegetables (tomato and beet root) by oxalate decomposition method. Zinc oxide solution was prepared by mixing of equimolar concentration of zinc source and oxalic acid. Dried fruit and vegetables samples were ground into powder and analyze to higher temperature like $600^{\circ} \mathrm{C}$. Powders were sieved using 2 micrometer sieve then $5 \%(\mathrm{v} / \mathrm{v})$ extracts were prepared from respective powders. While stirring of $0.2 \%$ nano scale zinc oxide solution, $1 \%$ gum solution was added. Prepared 5\% extract was added slowly with string and heating. Final solution was made up to $100 \mathrm{ml}$ and solution was kept at room temperature for one hour for stabilization.

\section{Physico-chemical analysis}

NFCs extracted were subjected to analysis soon after their extraction for parameters like yield, colour quality, concentration, zinc, total carotene, anthocyanin, lycopene and total betalain content. Yield of colour was estimated using Weighment method on dry weight basis. Colour quality of the samples was estimated by using Hunterlab calorimeter (Colour Quest XE hunter Lab, USA). The procedure for estimation of zinc was given by Garcia et al., (1974). The concentration of the colour was estimated by spectrophotometer as given by Jayaraman (1996). Procedures for estimation of total carotene, anthocyanin, lycopene and total betalain content were given by Ranganna (1986).

\section{Physical quality attributes}

\section{Determination of particle size}

\section{Scanning Electron Microscope (SEM) Protocol}

Samples were exposed against $2.5 \%$ gluteraldehyde in $0.1 \mathrm{M}$ phosphate buffer $(\mathrm{pH}$ 7.2) for $1 \mathrm{hr}$ at room temperature. Dehydrated in silica dessicator for $1 \mathrm{hr}$. The processed samples were mounted over the stubs with double-sided carbon conductivity tape, and a thin layer of gold coat over the samples were done by using an automated sputter coater (Model-JEOL JFC-1600) for 3 minutes and scanned under Scanning Electron Microscope (SEM - Model: JOEL-JSM 5600) at required magnifications (John and Lonnie, 1998).

\section{FT-IR measurements}

The FT-IR measurements of the natural colour encapsulated nanoparticles were carried out with TENSOR-27 (Bruker). To remove any free biomass residue or compound that is not the capping ligand of 
the nanoparticles, the residual solution of 100 $\mathrm{ml}$ after reaction was centrifuged at 15000 rpm for $15 \mathrm{~min}$ and the resulting suspension was redispersed in $10 \mathrm{ml}$ sterile distilled water. The centrifuging and redispersing process was repeated three times. Thereafter, the purified suspension was freeze dried to obtain dried powder. Finally, the dried nanoparticles were analyzed.

\section{Statistical analysis}

The data were analyzed for difference of significance by ANOVA used CRD and CD values are presented.

\section{Results and Discussion}

\section{Drying of samples and preparation of fine powder}

The yield of powder obtained after drying and grinding of samples is given in table 1 .

\section{Particle size and structure}

\section{SEM}

The NFCs synthesized from selected fruits (papaya and black grapes) and vegetables (tomato and beet root) were subjected to scan under Scanning Electron Microscope (SEM). From the images scanned with scanning electron microscope, it was found that the nano particles are spherical and agglomeralated in nature.

They are found intact with the coating material (Zno). The coating material is highly thick holding the nano particles inside. It was also observed that the size of the colour particles were in nano meters whereas the size of the coating material was in micro meters which showed that the zinc oxide was highly coated around the nano particles. The size of the NFCs obtained is given in table 2.
The results in the above table indicated that the size of the NFCs varied from sample to sample. The size of the NFCs synthesized from papaya ranged from 695.0-723.0 nm, from black grapes $(668.0-796.0 \mathrm{~nm})$, from tomato (772.0-965.0 $\mathrm{nm}$ ) and from beet root it ranged from 859.0-991.0 $\mathrm{nm}$. The average size of the particles were 713.0, 736.0, 859.0 and $925.0 \mathrm{~nm}$ in papaya, black grapes, tomato and beet root respectively.

\section{FT-IR measurements}

FT-IR results revealed that absorption bands were present at $3349,1635 \mathrm{~cm}^{-1}$ in NFCs of grape, tomato and papaya. The absorption band at $3349 \mathrm{~cm}^{-1}$ is assigned to the $\mathrm{N}-\mathrm{H}$ group or primary amides which are present in the respective colour extract. This also indicates the presence of alcohols with free $\mathrm{OH}$.

The absorption band $1635 \mathrm{~cm}^{-1}$ corresponds to the presence of nitrites and tertiary amides. Whereas, the absorption band $2102 \mathrm{~cm}^{-1}$ which is present in the sample Beet root NFC is assigned to the aromatic isonitriles which is absent in the other samples tested.

The results indicated that the colour of the respective extract was clearly encapsulated by the zinc nano particles. According to Cross, 1960 for trans fatty acid absorption bands were present at $1000-950 \mathrm{~cm}^{-1}$ and for cis fatty acid at 780- $680 \mathrm{~cm}^{-1}$ (Figs. 1-4).

\section{DLS and zeta potential measurements}

The particle size (DLS) and zeta potential measurements of the prepared samples were carried out using Nanopartica, SZ-100 (HORIBA). The hydrodynamic radius of the colour encapsulated nanoparticles was recorded as $123 \mathrm{~nm}, 232 \mathrm{~nm}, 385 \mathrm{~nm}, 1005 \mathrm{~nm}$ corresponds to Papaya, Tomato, Grapes and Beet root respectively. 
The sizes (hydrodynamic radius) of NFCs synthesized are in good correlation with the sizes measured under SEM.

The higher zeta potential values (Grape: 40.5mV, Tomato: $-36.5 \mathrm{mV}$, Papaya: $-32.7 \mathrm{mV}$ and Beatroot: $-41 \mathrm{mV}$ ) for all the samples tested indicate the high stability of the formed particles.

\section{Yield}

Yield of NFCs synthesized from selected fruits (papaya and black grapes) and vegetables (tomato and beet root) was calculated and recorded in the table 3 .

Results illustrated in the table 3 indicated that the yield of nano particle solution was 160.0 $\mathrm{ml}$ from $8.0 \mathrm{gm}$ of dry powder of papaya, $230.0 \mathrm{ml}$ from $11.5 \mathrm{gm}$ of black grapes, 120.0 $\mathrm{ml}$ from $6.0 \mathrm{gm}$ of tomato and $240.0 \mathrm{ml}$ from $12 \mathrm{gm}$ of beet root for $100 \mathrm{gm}$ of fresh sample.

\section{Concentration}

The results obtained for concentration of NFCs from selected fruits (papaya and black grapes) and vegetables (tomato and beet root) is given in the table 4 .

In beet root, the concentration of colour was found to be higher (7.10), followed by black grapes (6.67), papaya (4.38) and least was for tomato (3.39). Between the vegetable samples the concentration of colour was found to be higher in beet root (7.10) and lower in tomato (3.39). In fruit samples the concentration of colour was found to be higher in black grapes (6.67) followed by papaya (4.38). The values obtained in the present study for concentration are much higher compared to the value reported by Priya Mandhana et al., (2007). This may be mainly due to the synthesis of the colour nano particles with very small size and large surface area to volume ratio.

Table.1 Yield of powder obtained from the given samples after drying and grinding

\begin{tabular}{|l|c|c|c|c|}
\hline \multicolumn{1}{|c|}{ Sample Sample } & Papaya & Black grapes & Tomato & Beet root \\
\hline $\begin{array}{l}\text { Weight of powder } \\
\text { in (gm)/1kg of fresh sample }\end{array}$ & $80.0(8.0)$ & $115.0(11.5)$ & $60.0(6.0)$ & $120.0(12.0)$ \\
\hline
\end{tabular}

* Figures in parenthesis indicate percentages.

Table.2 Size of NFCs obtained from the selected fruits (papaya and black grapes) and vegetables (tomato and beet root)

\begin{tabular}{|c|c|c|}
\hline Sample & Range(nm) & Average (nm) \\
\hline Papaya & $695.0-723.0$ & 713.0 \\
\hline Black grapes & $668.0-796.0$ & 736.0 \\
\hline Tomato & $772.0-965.0$ & 859.0 \\
\hline Beet root & $859.0-991.0$ & 925.0 \\
\hline
\end{tabular}

Table.3 Yield of NFCs synthesized from selected fruits (papaya and black grapes) and vegetables (tomato and beet root)

\begin{tabular}{|c|c|c|c|}
\hline Sample & $\begin{array}{c}\text { Weight of the fresh } \\
\text { sample } \\
(\mathbf{g m})\end{array}$ & $\begin{array}{c}\text { Weight of the } \\
\text { dry powder } \\
\text { (gm) }\end{array}$ & $\begin{array}{c}\text { Volume of nano } \\
\text { particle solution } \\
(\mathbf{m l})\end{array}$ \\
\hline Papaya & 100.0 & 8.0 & 160.0 \\
\hline Black grapes & 100.0 & 11.5 & 230.0 \\
\hline Tomato & 100.0 & 6.0 & 120.0 \\
\hline Beet root & 100.0 & 12.0 & 240.0 \\
\hline
\end{tabular}


Table.4 Concentration of NFCs from selected fruits (papaya and black grapes) and vegetables (tomato and beet root)

\begin{tabular}{|c|c|c|c|c|}
\hline Sample & Papaya & Black grapes & Tomato & Beet root \\
\hline Concentration & 4.38 & 6.67 & 3.39 & 7.10 \\
\hline
\end{tabular}

Table.5 Colour quality of NFCs synthesized from selected fruits (papaya and black grapes) and vegetables (tomato and beet root)

\begin{tabular}{|c|c|c|c|}
\hline Sample & Light (L) & Hue (a) & Brightness (b) \\
\hline Papaya & 14.55 & 3.33 & 4.59 \\
\hline Black grapes & 16.56 & 3.59 & 8.53 \\
\hline Tomato & 14.26 & 2.73 & 5.45 \\
\hline Beet root & 13.36 & 4.56 & 5.34 \\
\hline
\end{tabular}

Table.6 Zinc content in the NFCs synthesized from selected fruits (papaya and black grapes) and vegetables (tomato and beet root)

\begin{tabular}{|c|c|c|c|c|}
\hline Sample & Papaya & Black grapes & Tomato & Beet root \\
\hline $\begin{array}{c}\text { Zinc content } \\
\text { (mg/100gm) }\end{array}$ & 3.94 & 6.81 & 2.95 & 7.51 \\
\hline
\end{tabular}

Table.7 Quantity of bio active compounds in NFCs synthesized from selected fruits (papaya and black grapes) and vegetables (tomato and beet root)

\begin{tabular}{|c|c|c|}
\hline Bioactive compounds & O.D value & Content in (100gm) \\
\hline Total carotenes (papaya) & 0.31 & $92.16 \mu \mathrm{g}$ \\
\hline Anthocyanins (black grapes) & 0.27 & $118.91 \mathrm{mg}$ \\
\hline Lycopene (tomato) & 0.125 & $4.68 \mathrm{mg}$ \\
\hline Betalains (beet root) & 2.2 & $5.28 \mathrm{mg}$ \\
\hline
\end{tabular}

Fig.1 FT-IR spectrum of Papaya's NFC

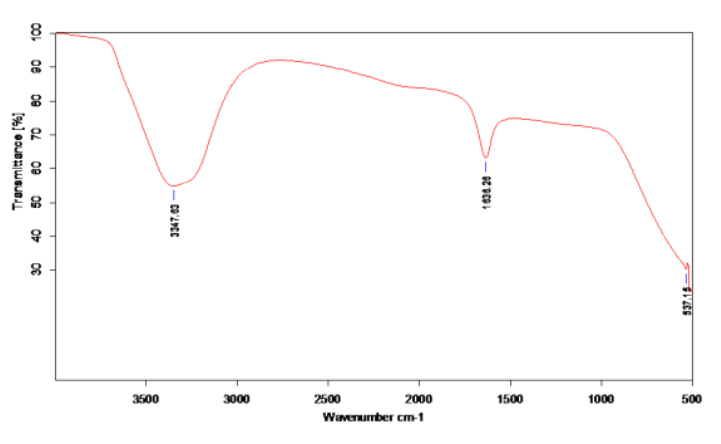

Fig.2 FT-IR spectrum of Black grapes's NFC

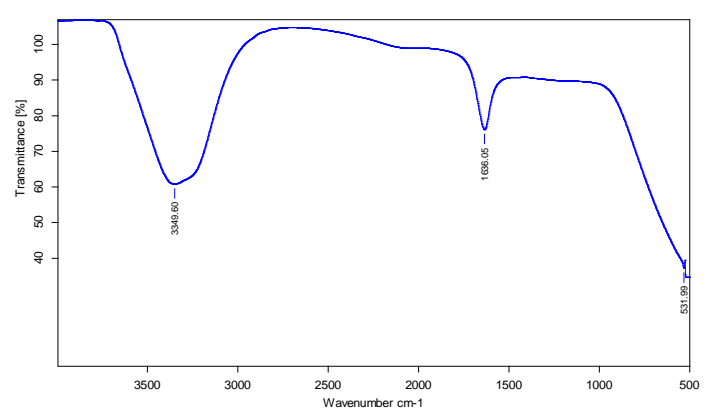


Fig.3 FT-IR spectrum of Tomato's NFC FRONTIER

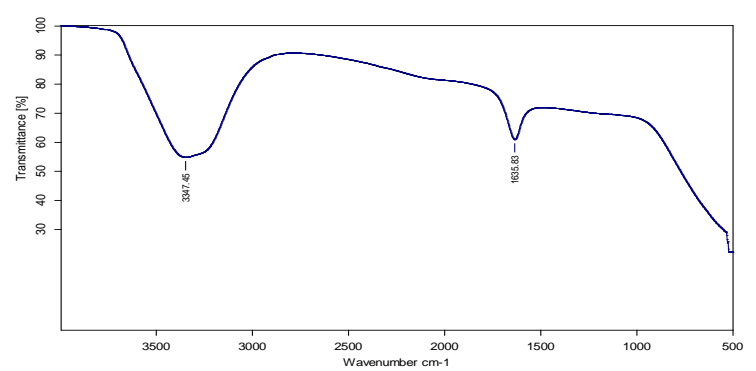

Colour quality

The colour quality of NFCs synthesized from selected fruits (papaya and black grapes) and vegetables (tomato and beet root) is given in table 5 .

The colour value was mainly determined in the form of light, hue and brightness. Among the vegetable samples lightness was found to be higher for NFC with tomato (14.26\%) followed by NFC with beet root (13.36\%). In the fruit samples lightness was found to be higher in NFC with black grapes $(16.56 \%)$ and lower in NFC with papaya $(14.55 \%)$. The values for lightness for all the NFCs were extended nearly towards ' 0 ' value i.e., black indicating good colour quality.

The + a (Hue) value which indicates more of redness and less of greenness was higher for beet root NFC (4.56\%) compared to NFC with tomato $(2.73 \%)$ among vegetable samples. In fruit samples hue value was higher for NFC with black grapes $(3.59 \%)$ compared to NFC with papaya (3.33\%). Between the vegetable samples the brightness was found to be higher for NFC with tomato $(5.45 \%)$ and lower for NFC with beet root $(5.34 \%)$ and in fruit samples higher for NFC with black grapes $(8.53 \%)$ compared to NFC with papaya $(4.59 \%)$.

\section{Zinc}

The nano particles synthesized from selected fruits (papaya and black grapes) and
‘Fig.4 FT-IR spectrum of Beet root's NFC

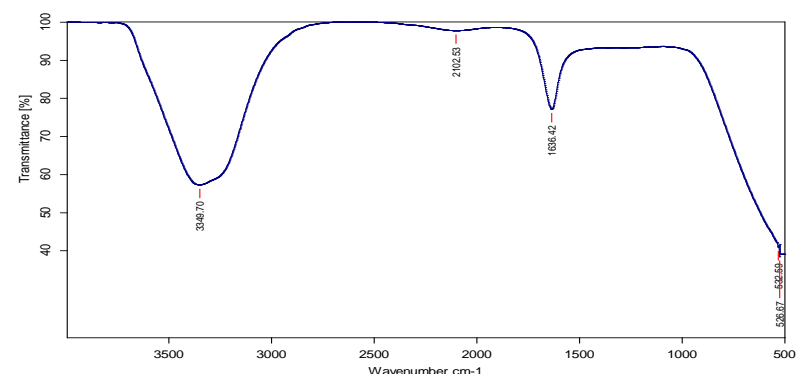

vegetables (tomato and beet root) in the present study are coated with zinc oxide. Hence zinc was estimated in the NFCs to know the amount of zinc that is present in the given nano particle solution. As zinc rich foods are tend to be expensive, the daily intakes of zinc was much lesser to the requirement. The recommended daily intake of zinc is $15 \mathrm{mg} /$ day. The amount of zinc in the given NFCs of selected fruits (papaya and black grapes) and vegetables (tomato and beet root) is given in the table 6 .

Results illustrated in the table 6 indicated that the zinc content in NFCs synthesized from papaya was $3.94 \mathrm{mg} / 100 \mathrm{gm}, 6.81 \mathrm{mg}$ in black grapes, $2.95 \mathrm{mg}$ in tomato and $7.51 \mathrm{mg} / 100 \mathrm{gm}$ in beet root. In fresh samples of tomato and beet root the zinc content was 0.41 and 0.91 respectively where as in papaya and black grapes it was not reported (Gopalan et al., 2007). When compared to the above values, it was observed that, the Zinc content of NFCs synthesized was higher indicating the significance of NFCs in enhancing the Zinc content of the food products. Zinc and zinc oxide were used as nutritional additives and antimicrobial agents in food packaging (Brunner, 2006). Hence these NFCs also can be used as nutritional additives and also as antimicrobial agents.

\section{Bioactive compounds}

The quantity of bio active compounds were estimated in the NFCs synthesized from selected fruits such as total carotenes (papaya) 
and anthocyanins (black grapes) and vegetables such as lycopene (tomato) and betalains (beet root) and results are given in table 7 .

Results in the table 7 indicated that the total carotene content in NFC with papaya was $92.16 \mu \mathrm{g} / 100 \mathrm{gms}$. The anthocyanin content in NFC with black grapes was 118.91 $\mathrm{mg} / 100 \mathrm{gm}$. The lycopene content in NFC with tomato was $4.68 \mathrm{mg}$ and betalain content in NFC with beet root was $5.28 \mathrm{mg} / 100 \mathrm{gm}$.

Thus it can be concluded that it is feasible to synthesize NFCs from dehydrated powders of selected fruits (papaya and black grapes) and vegetables (tomato and beet root) with good physico chemical (yield, colour quality, concentration, zinc and bio active compounds) properties.

\section{References}

Brunner, T., Piusmanser, P., Spohn, P., Grass, R., Limbach, L., Ruinink, A.B and Stark, W.2006. In Vitro

Cytotoxicity of Oxide Nanoparticles: Comparison to Asbestos, Silica, and the Effect of Particle Solubility. Environmental Science and Technology. 40:4374-4381.

Chattopadhyay Pritam., Sandipan Chatterjee and Sukanta K. Sen. 2008. Biotechnological potential of natural food grade biocolorants. African Journal of Biotechnology: 7 (17). 2972-2985.

Enculescu, I., Matei, E., Sima, M., Neumann, R., Granville, S., Ansermet, J.P. 2008. Preparation and Properties of

Cobalt Doped $\mathrm{ZnO}$ Nanowires. IEEE
Transactions on Magnetics. 44 911): 2678-2680, ISSN 0018-9464.

Gardener, E. 2002. "Brainy Food: Academia, Industry Sink Their Teeth into Edible Nano." Small Times. June 21.

Ghorpade, V. M., Deshpande, S. S and Salunkhe, D. K. 1995. Food colours in Food additive toxicology. J. Maga and T. Anthony (Eds). Marcel Dekker. New York: 179-233.

Gopalan, C., Rama Sastri, B. V and Balasubramanian, S. C. 2007. Nutritive value of Indian Foods. National Institute of Nutrition. Indian Council of Medical Research, Hyderabad: 68-73.

John, J. Bozzola and Lonnie, D. Russel. 1998. Electron Microscopy Principles and Techniques for Biologists $2^{\text {nd }}$ edition. Jones and Bartlett Publishers, Sudbury, Massachusetts.19-24, 54-55 and 63-67.

Miyazaki, K, Islam, N. 2007. Nanotechnology systems of innovation - An analysis of industry and academia research activities. Technovation. 27: 661-671.

Paul, R., Malanker, J. V and Naik, S. R. 1996. Textile dyer and printer. 23(10): 16.

Priya Mandhana and Uma maheswari, K. 2007. Extraction, stability and utilization of bio food colours from pumpkin (Curcubita maxima) and prickly pear (Opuntia lasiacantha), M.Sc thesis Acharya N.G. Ranga Agricultural University.

Ranganna, S.1986. Handbook of Analysis and Quality Control for Fruit and Vegetable Products, 2nd ed. Tata McGraw-Hill, New Delhi, India.

Stoimenov, P.K., Klinger, R.L., Marchin, G.L and Klabunde, K.J. 2002. Metal oxide nanoparticles as bactericidal agents. Langmuir. 18: 6679-6686.

\section{How to cite this article:}

Srilatha, P., Butti Prabhakar, K. Umamaheswari and Prasad, T.N.V.K.V. 2017. Analysis of Physico-Chemical Properties of Natural Food Colours from Fruits and Vegetables. Int.J.Curr.Microbiol.App.Sci. 6(7): 1125-1131. doi: https://doi.org/10.20546/ijcmas.2017.607.136 